\title{
Dormência e germinação de sementes de Melaleuca alternifolia Cheel.
}

\author{
ANSELMINI, J.I.; DESCHAMPS, C.; GAVAZZA, M.I.A.; ZANETTE,F.; PANOBIANCO, M.* \\ Universidade Federal do Paraná (UFPR), Departamento de Fitotecnia e Fitossanitarismo, Rua dos Funcionários, \\ 1540, CEP: 80035-050, Curitiba-Brasil *maristela@ufpr.br
}

\begin{abstract}
RESUMO: A Melaleuca alternifolia Cheel. é uma espécie aromática de expressivo interesse econômico, em função da presença de óleo essencial armazenado no tecido foliar. As sementes, entretanto, apresentam baixo poder germinativo, o que tem dificultado a obtenção de novos materiais genéticos e o avanço tecnológico para produção no Brasil. O presente trabalho teve por objetivo determinar uma metodologia adequada para avaliar o poder germinativo de sementes de melaleuca. Para tanto, foram realizados dois experimentos, um em condições de laboratório e outro em casa-de-vegetação, avaliando-se diferentes tratamentos para promover a germinação da semente. O delineamento experimental empregado foi o inteiramente casualizado, com quatro repetições, sendo nove tratamentos em laboratório e sete em casa de vegetação; a comparação de médias foi realizada pelo teste Tukey, a $5 \%$ de probabilidade. Diante dos resultados obtidos, concluiu-se que a pré-embebição das sementes por 18h, em água, é o procedimento mais adequado, dentre os testados, para avaliar o poder germinativo da semente de melaleuca, sendo que em condições de casa de vegetação, o referido tratamento pode ser usado com os substratos areia ou Plantmax.
\end{abstract}

Palavras-chave: dormência, qualidade fisiológica, giberelina

\begin{abstract}
Dormancy and germination of Melaleuca alternifolia Cheel. seeds. Melaleuca alternifolia Cheel. is an aromatic species of high economic interest due to the presence of essential oil in its leaf tissue. However, its seeds have low germinative potential, which has made difficult the obtaining of new genetic materials and the technological advance for production in Brazil. The present work aimed to determine a suitable methodology to evaluate the germinative potential of Narrow-leaved Paperbark seeds. Thus, two experiments were carried out, one under lab conditions and other in greenhouse, in order to evaluate different treatments to stimulate seed germination. Experimental design was completely randomized, with four replicates; nine treatments were used in the lab and other seven in greenhouse. Means were compared by the Tukey's test at $5 \%$ significance. The obtained results suggest that pre-imbibition of seeds for $18 \mathrm{~h}$ in water is the most suitable procedure to evaluate the germinative potential of Narrow-leaved Paperbark seeds. Under greenhouse conditions, this treatment can be used with the substrates sand or Plantmax ${ }^{\circledast}$.
\end{abstract}

Key words: dormancy, physiological quality, gibberellin

\section{INTRODUÇÃO}

A melaleuca (Melaleuca alternifolia Cheel.), internacionalmente conhecida como "tea tree", é espécie aromática da família Myrtaceae, originária da Austrália, com grande interesse econômico devido à presença de óleo essencial armazenado no tecido foliar. O constituinte majoritário do óleo essencial é o terpinen-4-ol que confere propriedades medicinais, principalmente antifúngicas e antibacterianas, garantindo-lhe importância comercial (Vieira et al., 2004).

As indústrias farmacêuticas e de cosméticos fazem uso do óleo essencial de melaleuca em larga escala, sendo os principais centros consumidores a América do Norte e a Europa. O preço desse óleo encontra-se bastante elevado, resultado do monopólio produtivo australiano (Castro et al., 2005). AAustrália produz em média $400 \mathrm{t} \mathrm{ano}^{-1}$ sendo considerado o principal produtor mundial de óleo essencial de Melaleuca. No Brasil, a produção ainda é inexpressiva e as indústrias de cosméticos tendem a adquirir o produto importado, agregando valores na forma de cosméticos, produtos farmacêuticos e de higiene

Recebido para publicação em 09/07/08

Aceito para publicação em 19/01/10

Rev. Bras. Pl. Med., Botucatu, v.12, n.2, p.149-152, 2010. 
pessoal (Castro et al., 2005). Vários fatores contribuem para a baixa produção brasileira; dentre eles, pode ser citada a ausência de informações técnicas relacionadas à produção de mudas da espécie.

A melaleuca em condições naturais assume porte arbóreo, com até $8,0 \mathrm{~m}$ de altura; a casca é fina e macia; as folhas são simples e afiladas, com cerca de 2,0 cm de comprimento (Biasi \& Deschamps, 2009).

Embora seja possível propagar M. anternifolia vegetativamente, a partir de mini-estacas, a propagação via semente é de grande interesse para programas de melhoramento genético devido ao aumento da base genética da espécie e consequente obtenção de quimiotipos com rendimento e qualidade superiores de óleo essencial adaptados às condições nacionais. No entanto, as sementes da espécie apresentam baixo poder germinativo, o que dificulta a obtenção de novos materiais genéticos e o avanço tecnológico para produção no Brasil, ressaltando a importância do desenvolvimento de métodos práticos e eficientes para estimular a germinação das sementes.

Uma das prováveis causas da falta de germinação das sementes, verificada para a espécie, é o fenômeno da dormência, que pode ser conceituado como o estado de repouso fisiológico em que a semente, em razão da ação de fatores internos, apresenta mecanismos bloqueadores da germinação. A dormência se encerra quando o metabolismo, síntese e crescimento ativos são reiniciados (Marcos Filho, 2005).

Em razão da importância econômica e da ausência de informações sobre a propagação sexuada da espécie, o trabalho teve por objetivo determinar metodologia adequada para avaliar o poder germinativo das sementes de Melaleuca alternifolia Cheel, testando vários tratamentos para promoção da germinação.

\section{MATERIAL E MÉTODO}

Os experimentos foram conduzidos no Laboratório de Análise de Sementes e na casa-devegetação do Departamento de Fitotecnia e Fitossanitarismo, da Universidade Federal do Paraná, Setor de Ciências Agrárias, em Curitiba, no período de agosto a novembro de 2006. Foram utilizadas sementes de melaleuca, adquiridas de produtores do Estado de São Paulo.

O delineamento do experimento em laboratório foi inteiramente casualizado com nove tratamentos e quatro repetições com 50 sementes cada. Os tratamentos constaram de: 1) préembebição em água destilada por 18 horas, 2) préembebição em água por 18 horas + 48 horas pré- esfriamento a $5^{\circ} \mathrm{C}$; 3) pré-embebição em $100 \mathrm{mg} \mathrm{L}^{-1}$ $\mathrm{GA}_{3}$ por 18 horas; 4) pré-embebição em $100 \mathrm{mg} \mathrm{L}^{-1}$ de $\mathrm{GA}_{3}$ por $18 \mathrm{~h}+48 \mathrm{~h}$ de pré-esfriamento a $5^{\circ} \mathrm{C} ; 5$ ) pré-embebição em $200 \mathrm{mg} \mathrm{L}^{-1}$ de $\mathrm{GA}_{3}$ por $\left.18 \mathrm{~h} ; 6\right)$ préembebição em $200 \mathrm{mg} \mathrm{L}^{-1}$ de $\mathrm{GA}_{3}$ por $18 \mathrm{~h}+48 \mathrm{~h}$ de pré-esfriamento a $5^{\circ} \mathrm{C}$; 7) umedecimento do substrato com solução de nitrato de potássio $\left(\mathrm{KNO}_{3}\right)$ a $0,2 \%$; 8) umedecimento do substrato com solução de nitrato de potássio $\left(\mathrm{KNO}_{3}\right)$ a $0,2 \%+48 \mathrm{~h}$ de pré-esfriamento a $\left.5^{\circ} \mathrm{C} ; 9\right)$ testemunha (água destilada).

Para cada tratamento testado, as sementes foram colocadas para germinar em caixas de plástico $(11,0 \times 11,0 \times 3,5 \mathrm{~cm})$ sobre duas folhas de papel mataborrão umedecidas com 2,5 vezes a massa do substrato, a $20^{\circ} \mathrm{C}$, sob luz branca contínua. As avaliações foram efetuadas a cada quatro dias, num total de 16 dias, seguindo os critérios estabelecidos pelas Regras para Análise de Sementes (Brasil, 1992).

O experimento em casa-de-vegetação foi também realizado em delineamento experimental inteiramente casualizado, porém com sete tratamentos e quatro repetições com 50 sementes cada. Os tratamentos consistiram de 1) pré-embebição em água destilada por $18 \mathrm{~h}+$ substrato Plantmax $\left.{ }^{\circledR}, 2\right)$ préembebição em água destilada por $18 \mathrm{~h}+$ substrato areia, 3) pré-embebição em $50 \mathrm{mg} \mathrm{L}^{-1} \mathrm{GA}_{3}$ por $18 \mathrm{~h}+$ substrato Plantmax ${ }^{\circledast}$, 4) pré-embebição em $50 \mathrm{mg} \mathrm{L}^{-1}$ $\mathrm{GA}_{3}$ por $18 \mathrm{~h}$ + substrato areia, 5) pré-embebição em $100 \mathrm{mg} \mathrm{L}^{-1} \mathrm{GA}_{3}$ por $18 \mathrm{~h}$ + substrato Plantmax $\left.{ }^{\circledR}, 6\right)$ pré-embebição em $100 \mathrm{mg} \mathrm{L}^{-1} \mathrm{GA}_{3}$ por $18 \mathrm{~h}$ + substrato areia e 7) testemunha. A semeadura ocorreu em copos plásticos $(100 \mathrm{~mL})$ cheios até a borda com cada substrato, mantidos sob nebulização intermitente. A porcentagem de plântulas normais foi avaliada 30 dias após a semeadura.

A análise de variância foi realizada utilizando o programa estatístico ESTAT, sendo a comparação de médias efetuada pelo teste de Tukey a $5 \%$ de probabilidade. Os dados foram transformados em arc sen $\sqrt{x / 100}$.

\section{RESULTADO E DISCUSSÃO}

Em condições controladas de laboratório, os melhores tratamentos para promover a germinação das sementes de melaleuca foram a partir de préembebição em água por 18 horas, pré-embebição em água por $18 \mathrm{~h}+48 \mathrm{~h}$ de pré-esfriamento a $5^{\circ} \mathrm{C}$, préembebição em $100 \mathrm{mg} \mathrm{L}^{-1} \mathrm{GA}_{3}$ por 18 horas e préembebição em $100 \mathrm{mg} \mathrm{L}^{-1}$ de $\mathrm{GA}_{3}$ por $18 \mathrm{~h}+48 \mathrm{~h}$ de pré-esfriamento a $5^{\circ} \mathrm{C}$, apresentando médias entre 8 e 17\% de plântulas normais (Tabela 1). O tratamento com $\mathrm{KNO}_{3}$ proporcionou $2 \%$ de germinação. Vale salientar que nos tratamentos $\mathrm{KNO} 3+48 \mathrm{~h}$ de préesfriamento e testemunha, não houve germinação de sementes. 
TABELA 1. Germinação (\%) de sementes de Melaleuca alternifolia Cheel., submetidas a diferentes tratamentos (experimento em laboratório).

\begin{tabular}{|c|c|}
\hline Tratamentos & Germinação (\%) \\
\hline Pré-embebição em água por $18 \mathrm{~h}$ & $12 \mathrm{a}$ \\
\hline Pré-embebição em água por $18 \mathrm{~h}+48 \mathrm{~h}$ de pré-esfriamento a $5^{\circ} \mathrm{C}$ & $8 a b$ \\
\hline Pré-embebição em $100 \mathrm{mg} \mathrm{L}^{-1}$ de $\mathrm{GA}_{3}$ por $18 \mathrm{~h}$ & $17 a$ \\
\hline Pré-embebição em $100 \mathrm{mg} \mathrm{L}^{-1}$ de $\mathrm{GA}_{3}$ por $18 \mathrm{~h}+48 \mathrm{~h}$ de pré-esfriamento a $5^{\circ} \mathrm{C}$ & $10 a$ \\
\hline Pré-embebição em $200 \mathrm{mg} \mathrm{L}^{-1}$ de $\mathrm{GA}_{3}$ por $18 \mathrm{~h}$ & $1 \mathrm{c}$ \\
\hline Pré-embebição em $200 \mathrm{mg} \mathrm{L}^{-1}$ de $\mathrm{GA}_{3}$ por $18 \mathrm{~h}+48 \mathrm{~h}$ de pré-esfriamento a $5^{\circ} \mathrm{C}$ & $3 b c$ \\
\hline $\mathrm{KNO}_{3}$ & 2c \\
\hline $\mathrm{KNO}_{3}+48 \mathrm{~h}$ de pré-esfriamento a $5^{\circ} \mathrm{C}$ & $0 c$ \\
\hline Testemunha & $0 \mathrm{c}$ \\
\hline
\end{tabular}

O pré-esfriamento conduzido a $5-10^{\circ} \mathrm{C}$ visa ativar enzimas hidrolíticas que conduzem à síntese de giberelinas e/ou degradação de inibidores, modificando o balanço entre essas substâncias. Já as giberelinas atuam durante a hidrólise de reservas, estimulando a síntese de novo e a atividade enzimática; também contribuem para a superação de exigências de luz e/ou baixas temperaturas, favorecem a expansão celular e o crescimento da plântula e a ampliação da faixa de temperatura ótima para a germinação (Marcos Filho, 2005).

Segundo Taiz \& Zeiger (2004), algumas sementes requerem luz ou frio para induzir o processo de germinação; em tais sementes, essa dormência pode, muitas vezes, ser quebrada pela aplicação de giberelina.

Por outro lado, os tratamentos com maior concentração de $\mathrm{GA}_{3}\left(200 \mathrm{mg} \mathrm{L}^{-1}\right)$ e com $\mathrm{KNO}_{3}$ resultaram em médias de germinação não satisfatórias, não diferindo estatisticamente da testemunha. Esse fato pode indicar efeito fitotóxico do regulador, devido à concentração elevada.

No experimento de casa-de-vegetação, o tratamento de pré-embebição em água por $18 \mathrm{~h}$, utilizando substrato areia, foi o único que diferiu significativamente da testemunha, revelando maior porcentagem de emergência de plântulas (Tabela 2).

Um fator determinante na porcentagem final de germinação e emergência de plântulas é o substrato, devendo ser considerados alguns fatores para a sua escolha, tais como estrutura, aeração, capacidade de retenção de água, tamanho da semente, teor de nutrientes essenciais, infestação de patógenos, facilidade de obtenção e custo do material utilizado (Popinigis, 1977; Danner et al., 2007).

Rayachhetry et al. (1998) e Hartman (1999) constataram baixo potencial germinativo em estudo com sementes de Melaleuca quinquenervia. Robinson et al. (2006), trabalhando com Melaleuca ericifolia, verificaram que o maior percentual de germinação ocorreu em semeadura superficial, no escuro, a $20^{\circ} \mathrm{C}$; no entanto, os autores concluíram que a viabilidade das sementes foi baixa, sugerindo mais estudos sobre a germinação da espécie.

Na Figura 1 está apresentada a distribuição da germinação das sementes ao longo das datas de

TABELA 2. Emergência de plântulas (\%) de Melaleuca alternifolia Cheel. após diferentes tratamentos da semente (experimento em casa-de-vegetação).

\section{Tratamentos}

Pré-embebição em água por 18h, substrato Plantmax ${ }^{\circledR}$

Pré-embebição em água por $18 \mathrm{~h}$, substrato areia

Pré-embebição em $50 \mathrm{mg} \mathrm{L}^{-1}$ de $\mathrm{GA}_{3}$ por $18 \mathrm{~h}$, substrato Plantmax ${ }^{\circledR}$

Pré-embebição em $50 \mathrm{mg} \mathrm{L}^{-1}$ de $\mathrm{GA}_{3}$ por $18 \mathrm{~h}$, substrato areia

Pré-embebição em $100 \mathrm{mg} \mathrm{L}^{-1}$ de $\mathrm{GA}_{3}$ por $18 \mathrm{~h}$, substrato Plantmax ${ }^{\circledR}$

Pré-embebição em $100 \mathrm{mg} \mathrm{L}^{-1}$ de $\mathrm{GA}_{3}$ por $18 \mathrm{~h}$, substrato areia

Testemunha

\section{Emergência de plântulas em casa de vegetação (\%)}

$3 a b$

6 a

$3 a b$

$4 a b$

$5 a b$

$3 a b$

$0 \mathrm{~b}$

Médias seguidas pela mesma letra na coluna não diferem entre si pelo teste de Tukey, a 5\% de probabilidade. 


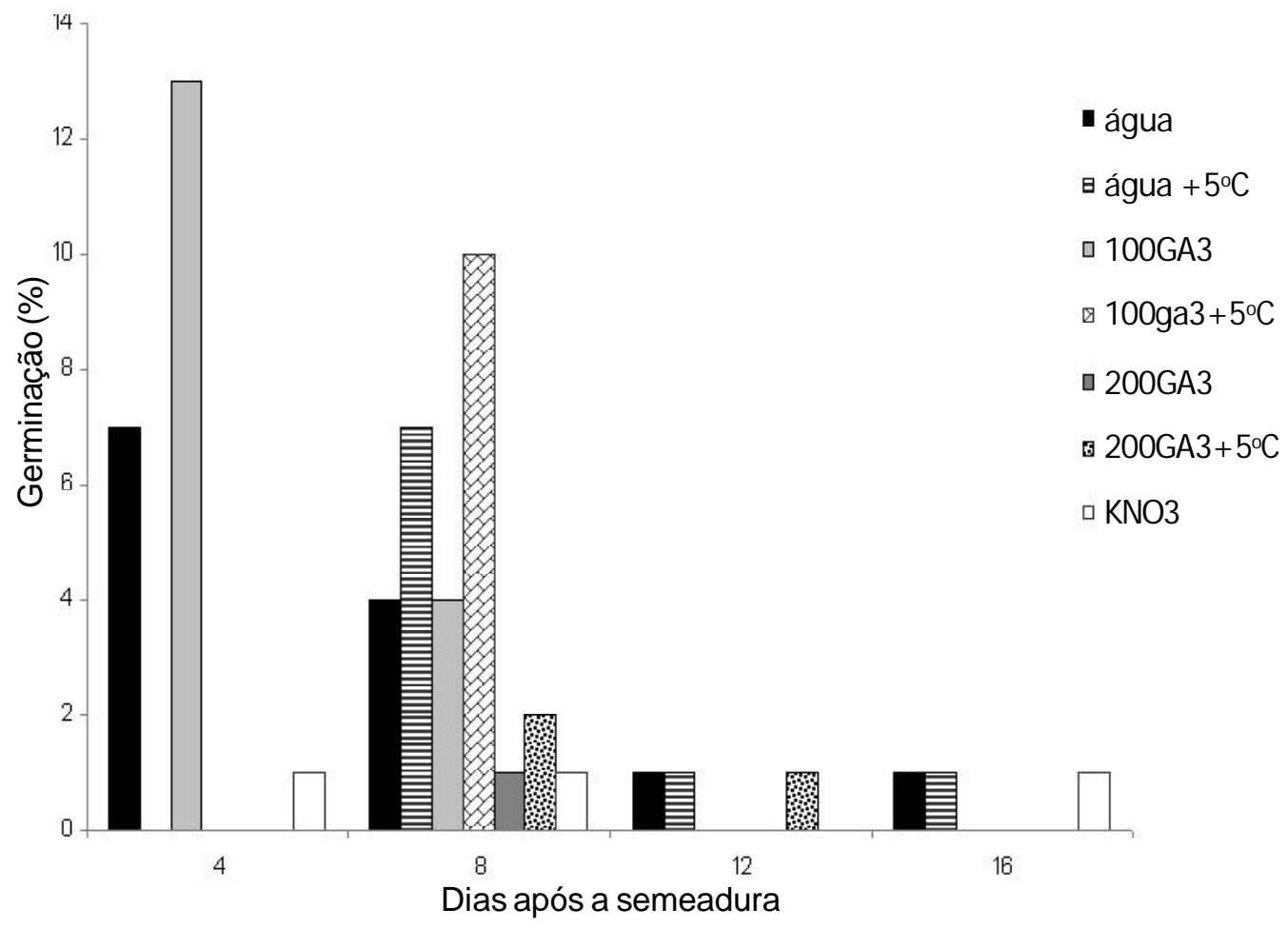

FIGURA 1. Germinação de sementes de M. alternifolia, submetidas a diferentes tratamentos pré-germinativos, em função das datas de avaliação (4, 8, 12 e 16 dias).

avaliação do teste. Pode-se observar que oito dias após a semeadura foi o período de tempo que revelou a maior porcentagem de plântulas normais e que, após 16 dias, não houve mais germinação, sugerindo que a primeira e a última contagem para o teste de geminação da espécie possam ser efetuadas, respectivamente, nas referidas datas.

\section{CONCLUSÃO}

A pré-embebição de sementes de melaleuca por $18 \mathrm{~h}$ em água é o procedimento mais adequado, dentre os testados, para avaliar o poder germinativo da semente de melaleuca, sendo que em condições de casa-de-vegetação, o referido tratamento pode ser usado com os substratos areia ou Plantmax.

\section{REFERÊNCIA}

BIASI, L.A.; DESCHAMPS, C. Plantas aromáticas: do cultivo à produção de óleo essencial. Curitiba: Layer Studio Gráfico e Editora Ltda., 2009. 106p.

BRASIL. Ministério da Agricultura. Regras para análise de sementes. Brasília: SNDA/DNDV/CLAV, 1992. 365p. CASTRO, C. et al. Análise econômica do cultivo e extração do óleo essencial de Melaleuca alternifolia Cheel. Revista Árvore, v.29, n.2, p.241-9, 2005.
DANNER, M.A. et al. Formação de mudas de jabuticabeira (Plinia sp.) em diferentes substratos e tamanhos de recipientes. Revista Brasileira de Fruticultura, v.29, n.1, p.179-82, 2007.

HARTMAN, J.M. Factors influencing establishment success of Melaleuca quinquenervia (Cav.) S.T. Blake in Everglades National Park. In: JONES, D.T.; GAMBLE, B.W. (Eds.). Florida's garden of good and evil: Proceedings of a Joint Conference of the Exotic Pest Plant Council and the Florida Native Plant Society. West Palm Beach: South Florida Water Management District, 1999. p.217-26.

MARCOS FILHO, M. Fisiologia de sementes de plantas cultivadas. Piracicaba: FEALQ, 2005. 495p. POPINIGIS, F. Fisiologia de sementes. Brasília: AGIPLAN, 1977. 289p.

RAYACHHETRY, M.B.; VAN, T.K.; Center, T.D. Regeneration potential of the canopy-held seeds of Melaleuca quinquenervia in south Florida. International Journal of Plant Sciences, v.159, p. 64854, 1998.

ROBINSON, R.W.; BOON, P.I.; BAILEY, P. Germination characteristics of Melaleuca ericifolia Sm. (swamp paperbark) and their implications for the rehabilitation of coastal wetlands. Marine and Freshwater Research, v.57, p.703-11, 2006.

TAIZ, L.; ZEIGER, E. Fisiologia vegetal. 3.ed. Porto Alegre: Artmed, 2004. 719p.

VIEIRA, T. R. et al. Constituintes químicos de Melaleuca alternifolia (Myrtaceae). Química Nova, v.27, n.4, p.536-9, 2004. 